Int. J. Electrochem. Sci., 13 (2018) 9759 - 9770

\title{
Electrodeposition of Lead from 1-Methylimidazolium Trifluoromethylsulfonate Ionic Liquid
}

\author{
$\operatorname{Min} L i^{1,2, *}$, Ying $L i^{1,2, *}$ \\ ${ }^{1}$ School of Metallurgy, Northeastern University, Shenyang 110819, China \\ ${ }^{2}$ Liaoning Key Laboratory for Metallurgical Sensor and Technology, Northeastern University, \\ Shenyang 110819, China

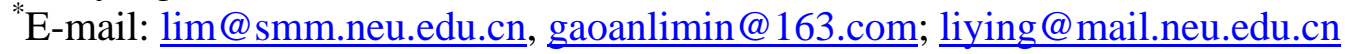

doi: $10.20964 / 2018.10 .28$

Received: 7 June 2018 / Accepted: 25 July 2018 / Published: 1 September 2018

In this work, it found that lead oxide $(\mathrm{PbO})$ can be dissolved well in 1-methylimidazolium trifluoromethylsulfonate (MIMTfO) ionic liquid. The electrodeposition of lead from PbO in MIMTfO ionic liquid was studied. Cyclic voltammetry studies showed that the reduction of $\mathrm{Pb}(\mathrm{II})$ is a irreversible and one-step reaction process. Chronoamperometry results presented that the nucleation mechanism of lead is fit instantaneous nucleation under diffusion control. The diffusion coefficient of $\mathrm{Pb}(\mathrm{II})$ at $373 \mathrm{~K}$ is approximately $3.6 \times 10^{-8} \mathrm{~cm}^{2} \mathrm{~s}^{-1}$. The electrodeposition experiments were conducted at $383 \mathrm{~K}$ and $393 \mathrm{~K}$ using potentiostatic electrolysis. A compact electrodeposit was obtained at $383 \mathrm{~K}$ in MIMTfO ionic liquid, which was confirmed to be metallic lead.

Keywords: lead; electrodeposition; ionic liquid; cyclic voltammetry; chronoamperometry

\section{FULL TEXT}

(C) 2018 The Authors. Published by ESG (www.electrochemsci.org). This article is an open access article distributed under the terms and conditions of the Creative Commons Attribution license (http://creativecommons.org/licenses/by/4.0/). 